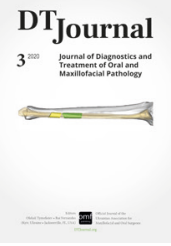

Salivary Glands | Head and Neck Ultrasound: Case Report

\title{
Foreign Body Retrograde Migration to the Intraglandular Duct of the Submandibular Gland with a Developing of Foreign Body-Induced Sialolithiasis: Analysis of Ultrasonography, Surgery, and Literature Published during Last 124 Years
}

\author{
Lilia A. Savchuka \& Oleksandr A. Nozhenkob,*
}

\section{SUMMARY}

We present a unique case of a vegetal foreign body retrograde migration to the intraglandular duct of the submandibular gland with a developing of foreign body-induced sialolithiasis in a 61-year-old woman. Analysis of ultrasound examination and operation are performed. Our foreign body's case represents an intermediate stage of complete sialolith formation around the foreign body nidus (synonym: scaffold). The paper summarizes the analysis of 28 cases with foreign body-induced sialoliths ( 27 cases from literature and a case of our team). Literature review which was based on the studies published during the last 124 years gave a possibility to classify the development of the 'foreign body-induced sialolithiasis' in 4 consecutive stages. Our case of the foreign body-induced sialolithiasis represents a second stage of this pathologic process when nidus is partially covered by calcifications.

a Physician of Ultrasound Investigation, Polyclinic, Kyiv Regional Clinical Hospital, Kyiv, Ukraine.

${ }^{b}$ Oral Surgeon, Center of Maxillofacial Surgery and Dentistry, Kyiv Regional Clinical Hospital, Kyiv, Ukraine.

*Corresponding author address: 1 Bahhovutivska Street, Kyiv 04107, Ukraine. Center of Maxillofacial Surgery and Dentistry, Kyiv Regional Clinical Hospital.

E-mail: alexdent@ukr.net (Oleksandr Nozhenko)
How to cite this article: Savchuk LA, Nozhenko OA. Foreign body retrograde migration to the intraglandular duct of the submandibular gland with a developing of foreign body-induced sialolithiasis: analysis of ultrasonography, surgery, and literature published during last 124 years. J Diagn Treat Oral Maxillofac Pathol 2020;4(3):53-9.

Paper received 12 February 2020

Accepted 14 March 2020

Available online 31 March 2020

https://dx.doi.org/10.23999/j.dtomp.2020.3.2.

(C) 2020 OMF Publishing, LLC. This is an open access article under the CC BY license (http://creativecommons.org/licenses/by-nc/4.0/). 
Obstructive sialadenitis caused by the foreign body intrusion into the duct of the gland can have an acute and chronic clinical course or exacerbation of a chronic form. ${ }^{1}$ Incredibly different foreign bodies inside the Wharton's ducts have been found and reported. Fingernail, ${ }^{2}$ vegetal nidus, ${ }^{3}$ thorn, ${ }^{4}$ piece of hair, ${ }^{5}$ fish bone, ${ }^{6,7}$ metal body, ${ }^{8}$ and other particles are published as foreign bodies of the submandibular gland duct which caused obstructive sialadenitis. In some foreign body cases, for example a fish bone, it was connecting several sialoliths. ${ }^{6}$ Study of Xie et $\mathrm{al}^{7}$ presented 13 patients which had fish bone nidus inside the sialoliths (synonyms: concrements, ${ }^{9,1}$ salivary stones, calculi $\left.{ }^{1,10}\right)$. All those reports proved one of the sialolithiasis theories, which describe a foreign body-induced sialolith formation. Despite the fact that in some cases the foreign bodies' are localized in the anterior/middle part of the duct, its migration to the intraglandular duct system is also possible and should be analyzed.

Retrograde passage of different foreign bodies into/inside the Wharton duct described in the recent publications: a $2.0 \mathrm{~cm}$ long barb-like metal body (which located at the posterior part of the Wharton's duct $)^{8}$ and $3.5 \mathrm{~cm}$ long wooden splinter ${ }^{11}$.

The purpose of our report is to present a unique case of a vegetal foreign body retrograde migration to the intraglandular duct of the submandibular gland with a developing of foreign body-induced sialolithiasis. Analysis of ultrasound examination, operation, and literature review are also highlighted. Our foreign body's case represents an intermediate stage of forming a complete sialolith around the foreign body nidus.

\section{CASE}

A 61-year-old Caucasian woman was referred to the Center of Maxillofacial Surgery and Dentistry with 4-day complaints: salivary colics and tissues enlargement in the area of right submandibular gland. Bimanual palpation revealed enlarged, firm and painful right submandibular gland. Upon the intraoral examination clear saliva milked from the orifices of both Whartons ' ducts. Sublingual mucosa also showed no signs of inflammation.

Preoperative ultrasonography was performed by an experienced ( 29 yrs) physician of ultrasound investigation (Lilia Savchuk) using $12-3 \mathrm{MHz}$ linear probe (model HD11 XE, Philips). Gray scale (synonym: B-mode) sonograms (Fig 1) showed 2-times enlarged right submandibular gland with a significantly dilated intraglandular duct system and $0.8 \times 0.3-\mathrm{cm}$ foreign body inside. Foreign body visualized as hyperechoic linear structure without artifact of acoustic shadowing typical for sialoliths.

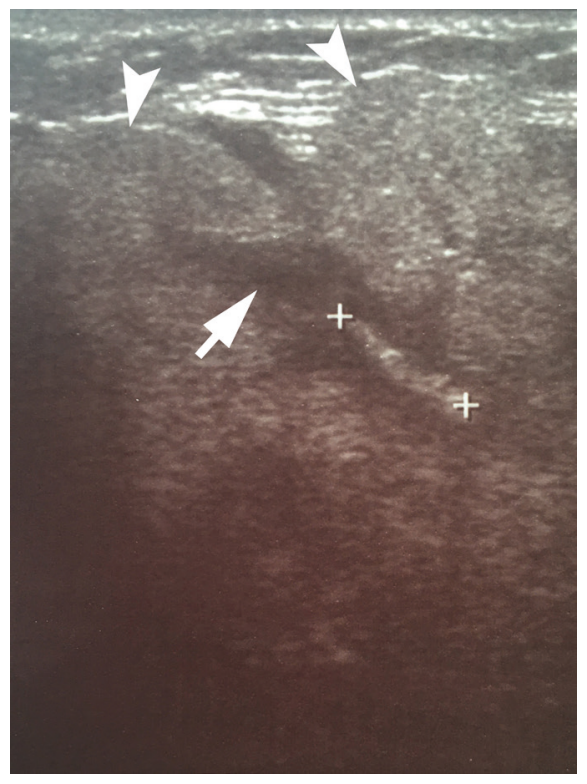

FIGURE 1. Preoperative gray scale sonogram shows an enlarged right submandibular gland (arrowheads) with a significantly dilated intraglandular duct system (arrow) and $0.8 \times 0.3$-cm foreign body inside, which is indicated by " + " calipers and visualized as hyperechoic linear structure without artifact of acoustic shadowing typical for sialoliths. 
Under the local anesthesia, a ductotomy in the posteriorpart of theright Wharton'sduct wasperformed and the foreign body was extracted. After removal, the foreign body undergone precise investigation by a surgeon (Oleksandr Nozhenko) which revealed a 0.8$\mathrm{cm}$ long green vegetal nidus (looked like a stem of a plant) with a multiple areas of attached calcifications (Fig 2). Intramuscular injections of ceftriaxone $1 \mathrm{~g} \times 2$ times per day and intraoral probiotics were prescribed simultaneously with rinsing by antiseptic solution during next 5 days after surgery. Post-operative period was smooth (i.e., uneventful recovery).

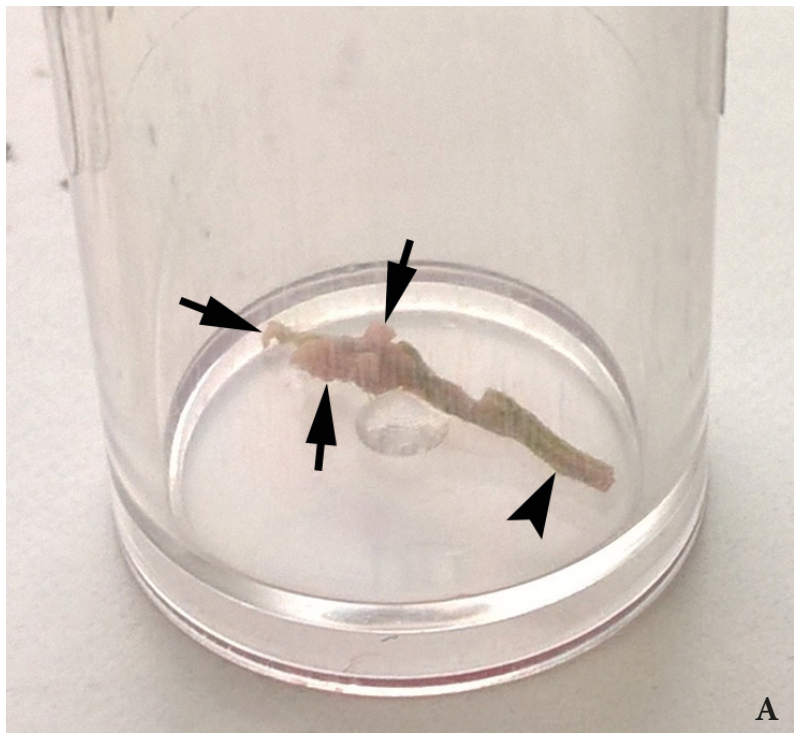

FIGURE 2. Foreign body after removal: A magnified view from different sides and multiple areas of attached calcifications (arrows).

\section{DISCUSSION}

Mechanical blockage of the ductal system and stasis of salivation describes the development of obstructive sialadenitis. If the foreign body intrusion was unrecognized by the patient and does not immediately cause complaints in a patient or patient received symptomatic treatment, the foreign body prolonged intraductal stay potentially can provoke formation of attached calcification around the foreign body's nidus and develop of foreign bodyinduced sialolithiasis.

Case studies indicate that foreign bodies can also penetrate parotid gland ducts without ${ }^{12}$ or with development of foreign body-induced sialolith ${ }^{13}$.

In contrary to smooth surface-foreign bodies, the bodies with irregular surface, like particles of the plants and fish bones, are more likely to transform into sialoliths.

Some of the particles originated from human body, like fingernail ${ }^{2,14}$ and hair ${ }^{5,15}$. Others were intruded upon eating the food, like fish bones. ${ }^{6,7,16-18}$ And a lot of foreign bodies of completely unexpected

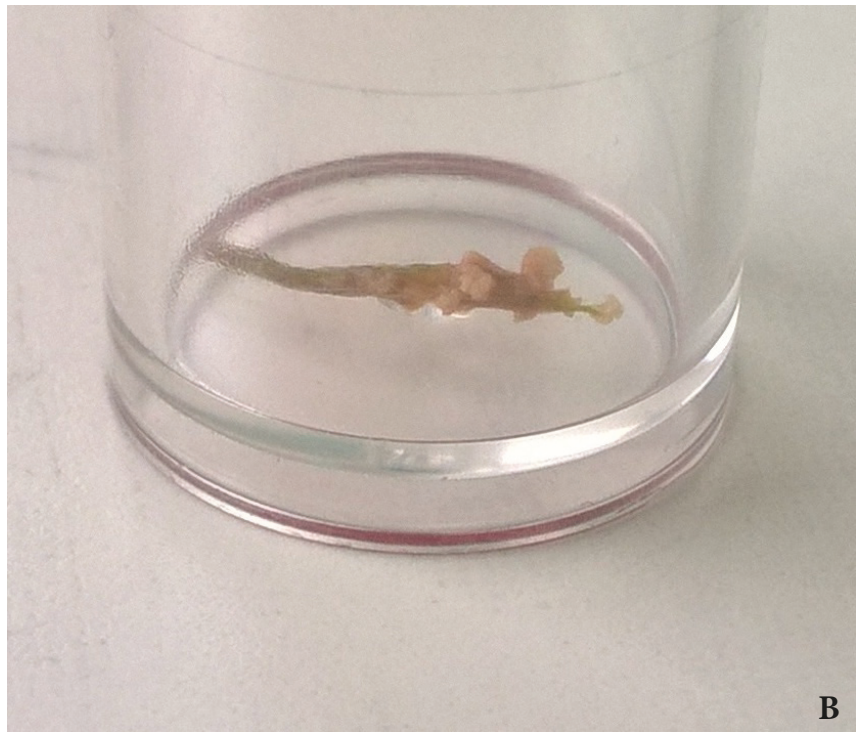

(A, B). A 0.8-cm long green vegetal nidus (arrowhead) with a rough surface origin like metal wire ${ }^{19}$, blade of grass ${ }^{20}$ or thorn ${ }^{4}$.

A thorough study of Loring W. Pratt showed the fundamental analysis of 15 literature sources from 1897 to $1968 .{ }^{10}$ Which revealed, among more than 37 cases with foreign bodies of the Wharton's duct $^{10}$, two patients with foreign bodies covered by calcifications $\mathrm{s}^{21,22}$. The oldest article reached the year 1897 when was reported a patient with sialitis (an old name of "sialadenitis") induced by a blade of grass without a stone formation. ${ }^{23}$

Reported, that foreign bodies can lead to the immediate insignificant complaints (the patients can feel an injection under the tongue at the moment of foreign body intrusion), ${ }^{1}$ and continue to behave as a "silent foreign body" even up to 12 months.

In some cases even a $3.5 \mathrm{~cm}$ long thin wooden splinter can migrate to the posterior part of the Wharton's with signs of obstructive sialadenitis but without sialolith formation around foreign body even after the 18 months of complaints. ${ }^{11}$ In other cases a prolonged foreign body intraductal stay can lead to the development of foreign bodyinduced sialolithiasis. As during the period of an 
intraductal localization of some foreign bodies with a rough surface, the salivary stones are formed by the precipitation of calcified structures around a foreign body-nucleus. We agreed with opinion of Derin et $\mathrm{al}^{18}$ who used another term for nidus - a scaffold. They describe intraductal fishbone which served as a scaffold for sialolth. ${ }^{18}$

In our opinion, a foreign body-induced sialolith formation is a more threatening condition for the course of obstructive sialadenitis. Because of a foreign body's volume increases due to the permanent precipitation of calcified structures around it. This fact provokes even severe blockage of the gland and stasis of the saliva. What also accelerate degenerative changes of the glandular tissue and increase the risk of exacerbation of the chronic obstructive sialadenitis.

Table 1 depicts completely different particles which served as a nidus upon foreign body-induced sialolith formation. To the table were gathered the cases which were published during last 124 years presenting the foreign body-induced sialolithiasis of the submandibular glands. The table was compiled based on our literature search and analysis of Loring W. Pratt, M.D. for the 1897-1968 period.

TABLE 1. Articles Describing the Foreign Body-Induced Sialoliths of the Submandibular Glands.

\begin{tabular}{|c|c|c|c|c|}
\hline \# & $\begin{array}{l}\text { Type of the Foreign Body } \\
\text { (i.e. Nucleus That is Made } \\
\text { of Foreign Body) }\end{array}$ & No. of Patients & Year of Publication & Title of the Article \\
\hline 1 & Blade of grass & 1 & 1937 & Salivary calculus containing a foreign body. ${ }^{21}$ \\
\hline 2 & Tooth brush bristle & 1 & 1959 & $\begin{array}{l}\text { Tooth brush bristle as a nucleus for calculus formation in } \\
\text { the hilum of the submaxillary gland. }{ }^{22}\end{array}$ \\
\hline 3 & $\begin{array}{l}\text { Vegetable matter with } \\
\text { calcium incrustation }\end{array}$ & 1 & 1967 & Unusual foreign body etiology of sialadenitis. ${ }^{24}$ \\
\hline 4 & Pine needle & 1 & \multirow{2}{*}{1968} & \multirow{2}{*}{ Foreign body of Wharton's duct with calculus formation. ${ }^{10}$} \\
\hline 5 & Broom straw & 1 & & \\
\hline 6 & Blade of grass & 1 & 1982 & $\begin{array}{l}\text { Submandibular salivary duct calculus secondary to a } \\
\text { foreign body. }{ }^{20}\end{array}$ \\
\hline 7 & Metal wire & 1 & 1984 & $\begin{array}{l}\text { A sialolithiasis formed around a metal wire in the } \\
\text { submandibular salivary duct. }{ }^{19}\end{array}$ \\
\hline 8 & Vegetal nidus & 1 & 2001 & Retrograde theory in sialolithiasis formation. ${ }^{3}$ \\
\hline 9 & Shrapnel & 1 & 2003 & $\begin{array}{l}\text { Shrapnel-induced sialolith-a rare etiology for sialadenitis: } \\
\text { Case report. }{ }^{25}\end{array}$ \\
\hline 10 & Thorn & 1 & 2005 & $\begin{array}{l}\text { Case of foreign body in Wharton's duct causing } \\
\text { silolithiasis. }\end{array}$ \\
\hline 11 & Fish bone & 1 & 2009 & Fish bone-induced sialolith. ${ }^{9}$ \\
\hline 12 & Facial hair & 1 & 2014 & Unusual case of a sialolith: a case report. ${ }^{15}$ \\
\hline 13 & Fish bone & 13 & 2014 & $\begin{array}{l}\text { Foreign body induced sialolithiasis treated by } \\
\text { sialoendoscopic intervention. }\end{array}$ \\
\hline 14 & Fish bone & 1 & 2015 & Fish bone induced sialolith in Wharton duct. ${ }^{18}$ \\
\hline 15 & Fish bone & 1 & 2018 & $\begin{array}{l}\text { Sialendoscopic removal of fish bone-induced sialoliths in } \\
\text { the duct of the submandibular gland. }{ }^{6}\end{array}$ \\
\hline 16 & $\begin{array}{l}\text { Vegetal nidus (stem of a } \\
\text { plant) }\end{array}$ & 1 & 2020 & $\begin{array}{l}\text { Foreign body retrograde migration to the intraglandular } \\
\text { duct of the submandibular gland with a developing } \\
\text { of foreign body-induced sialolithiasis: analysis of } \\
\text { ultrasonography, surgery, and literature published during } \\
\text { last } 124 \text { years. }\end{array}$ \\
\hline
\end{tabular}


The hair is perfectly described in 2009's sialoendoscopy report as a cause of obstructive sialadenitis of the submandibular gland. ${ }^{5}$ In 2014 the first case study presented a facial hair which served as a nidus for $\sim 6-\mathrm{mm}$ salivary stone formation. ${ }^{15}$

The same situation is with metallic foreign bodies. In some cases they are founded as a cause of obstructive sialadenitis without signs of sialolith formation, ${ }^{8}$ in others - sialolith forms around a metal wire ${ }^{19}$ or shrapnel ${ }^{25}$.

We supported the opinion of Sreetharan and Philip - ultrasound investigation may be a very good first line diagnostic modality. ${ }^{12}$ Upon ultrasonography sialoliths is usually visualized as hyperechoic semilunar bodies with an artifact of acoustic shadowing. Mucous plugs at ultrasound presented as a round shape isoechoic intraductal bodies without acoustic shadowing. ${ }^{26}$

2017 `s retrospective study of 659 salivary glands (486 submandibular and 173 parotid) revealed that sensitivity is of $94.7 \%$ and specificity of $97.4 \%$ for sonography in the patients with sialolithiasis. ${ }^{9}$

In our case the foreign body visualized as hyperechoic linear structure and the artifact of acoustic shadowing was not noted due to the partial calcifications around the vegetal nidus.
Summarizing the analysis of the published cases, the foreign body-induced sialolithiasis goes through 4 consecutive stages:

1. Calcium incrustations into foreign body (incrustations are visible only microscopically). ${ }^{24}$

2. Partially covered nidus (when calcifications are attached to different parts of the foreign body) (Fig 2). ${ }^{15}$ It can be considered as intermediate stage of sialolith formation.

3. Fully covered nidus (when cortex of calcifications covers the nidus from all sides).

4. Growth of sialolith 's cortex (this stage is pointed out based on the different sizes of sialoliths with the same size nidus).

And our case clearly shows that it's important to remember that those 4 stages should be distinguished. As upon the first stage, the organic foreign body can be completely invisible at X-ray/ computed tomography (in case of vegetal origin of foreign body) or showed no acoustic shadowing upon ultrasound.

Conclusion of two possible ways of pathological process development after intrusion of foreign body into the Wharton`s duct is represented in Figure 3.

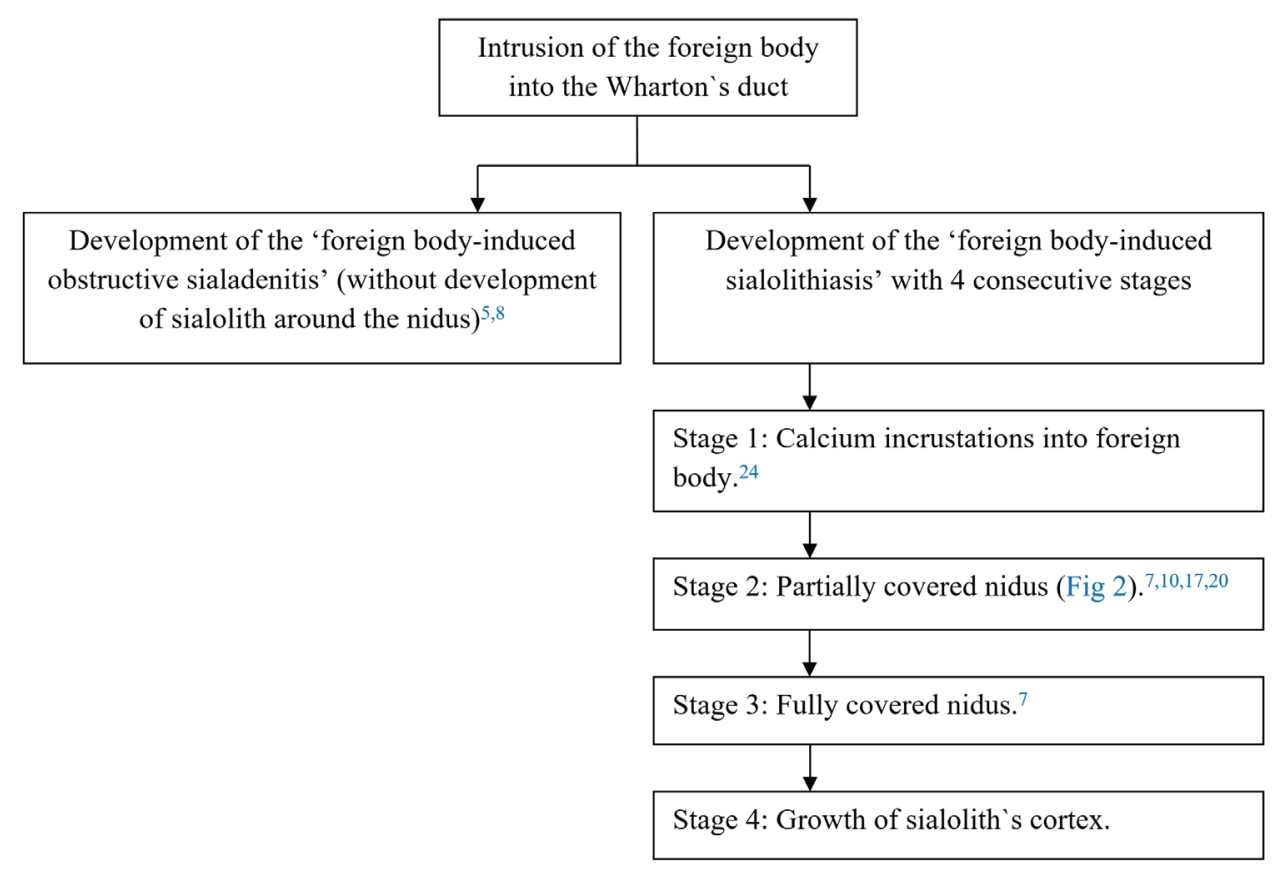

FIGURE 3. Flowchart displaying two possible ways of pathological process development inside the submandibular gland system after intrusion of the foreign body into the Wharton `s duct. 


\section{CONCLUSIONS}

Our paper summarizes the analysis of 28 cases with foreign body-induced sialolithiasis (27 cases from literature and a case of our team). Literature review which was based on the studies published during the last 124 years gave a possibility to classify the development of the 'foreign body-induced sialolithiasis' in 4 consecutive stages. Our case of the foreign body-induced sialolithiasis represents a second stage of this pathologic process when nidus is partially covered by calcinations. The report is heightened by the analysis of ultrasound features and macroscopic images.

\section{PATIENT CONSENT}

Not needed.

\section{CONFLICT OF INTERESTS}

The authors declare no conflict of interest.

\section{FUNDINGS}

No funding was received for this study.

\section{ACKNOWLEDGMENTS}

None.

\section{REFERENCES}

1. Tymofieiev OO. Manual of maxillofacial and oral surgery [Russian]. 5th ed. Kyiv: Chervona Ruta-Turs; 2012.

2. Modlin B. Foreign body (fingernail) as cause of acute submaxillary gland infection. Eye Ear Nose Throat Mon 1975;54(5):206-7.

3. Marchal F, Kurt AM, Dulguerov P, Lehmann W. Retrograde theory in sialolithiasis formation. Arch Otolaryngol Head Neck Surg 2001;127(1):66-8. https://doi.org/10.1001/archotol.127.1.66.

4. Bhavesh M. Case of foreign body in Wharton's duct causing silolithiasis. Indian J Otolaryngol Head Neck Surg 2005;57(4):322-3. http://dx.doi.org/10.1007/ BF02907699.

5. Ardekian L, Klain H, Peled M. Obstructive sialadenitis of submandibular gland due to foreign body successfully treated by sialoendoscopic intervention. J Oral Maxillofac Surg 2009;67(6):1337-9. https://doi. org/10.1016/j.joms.2008.12.059.
6. Iwai T, Sugiyama $S$, Hayashi $Y$, Oguri $S$, Hirota $M$, Mitsudo K, Tohnai I. Sialendoscopic removal of fish bone-induced sialolithsin the duct of the submandibular gland. Auris Nasus Larynx 2018;45(2):343-5. https:// doi.org/10.1016/j.anl.2017.03.010.

7. Xie L, Zheng L, Yu C, Yang C, Chen Z, Yun B, Kim E. Foreign body induced sialolithiasis treated by sialoendoscopic intervention. J Craniofac Surg 2014;25(4):1372-5. https://doi.org/10.1097/ SCS.0000000000000851.

8. Li P, Zhu H, Huang D. Detection of a metallic foreign body in the Wharton duct: a case report. Medicine (Baltimore) 2018;97(44):e12939. https://doi. org/10.1097/MD.0000000000012939.

9. Goncalves $M$, Schapher $M$, Iro $H$, Wuest $W$, Mantsopoulos K, Koch M. Value of sonography in the diagnosis of sialolithiasis: comparison with the reference standard of direct stone identification. $J$ Ultrasound Med 2017;36(11):2227-35. http://dx.doi. org/10.1002/jum.14255.

10. Pratt LW. Foreign body of Wharton's duct with calculus formation. Ann Otol Rhinol Laryngol 1968;77(1):88-93. http://dx.doi.org/10.1177/000348946807700109.

11. Chowdhary A, Kalsotra P, Parihar SS, Bhagat DR, Ali N. Rashid A. Foreign body in the Wharton's duct. JK Science 2005;7(2):61-2.

12. Sreetharan SS, Philip R. Unusual foreign body of parotid gland presenting assialolithiasis: casereportandliterature review. Case Rep Otolaryngol 2012;2012:367349. http:// dx.doi.org/10.1155/2012/367349.

13. Iwai $\mathrm{T}$, Izumi $\mathrm{T}$, Sugiyama $\mathrm{S}$, Watanabe $\mathrm{D}$, Kosugi Y, Mitsudo K. Sialendoscopic removal of gold filament thread-induced sialolith in the duct of the parotid gland. I Stomatol Oral Maxillofac Surg 2020:S2468-7855(20)30045-8. http://dx.doi. org/10.1016/j.jormas.2020.03.002.

14. Taneja M, Taneja MK. Foreign body Wharton's Duct. Indian J Otolaryngol Head Neck Surg 2011;63(3):3001. http://dx.doi.org/10.1007/s12070-011-0261-3.

15. Boynton TT, Lieblich SE. Unusual case of a sialolith: a case report. Oral Surg Oral Med Oral Pathol Oral Radiol 2014;117(1):e9-10. http://dx.doi. org/10.1016/j.0ooo.2012.03.020.

16. Abe K, Higuchi T, Kubo S, Oka M. Submandibular sialadenitis due to foreign body. $\mathrm{Br} J$ Oral Maxillofac Surg 1990;28(1):50-2. http://dx.doi. org/10.1016/0266-4356(90)90012-A.

17. Sato K, Umeno H. Fish bone-induced sialolith. Otolaryngol Head Neck Surg 2009;141(4):539-40. http://dx.doi.org/10.1016/j.otohns.2009.05.002.

18. Derin S, Sahan M, Kule M, Koseoglu S, Celik OI. Fish bone induced sialolith in Warthon duct. J Craniofac Surg 2015;26(7):e663-4. http://dx.doi.org/10.1097/ SCS.0000000000002075.

19. Takeda Y, Yahata C. A sialolithiasis formed around 
a metal wire in the submandibular salivary duct [in Japanese]. Shoni Shikagaku Zasshi 1984;22(3):712-5.

20. Watkins RM. Submandibular salivary duct calculus secondary to a foreign body. Br J Surg 1982;69(7):379. http://dx.doi.org/10.1002/bjs.1800690707.

21. Pilcher JA. Salivary calculus containing a foreign body. Arch. Otolaryngol 1937;26(5):531-3. http:// dx.doi.org/10.1001/archotol.1937.00650020585005.

22. Narayanan G. Tooth brush bristle as a nucleus for calculus formation in the hilum of the submaxillary gland. Indian Jour of Otol 1959;11(4):177-81. http:// dx.doi.org/10.1007/BF03047227.

23. Cosens C, Smith R. St. Bartholomew's Reports 1897;33:105.
24. Riccio FJ, Scavo VJ. Unusual foreign body etiology of sialadenitis. Arch Otolaryngol 1967;86(2):210-2. http:// dx.doi.org/10.1001/archotol.1967.00760050212019.

25. Ouellette AL, Slack CL. Shrapnel-induced sialolith-a rare etiology for sialadenitis: Case report. J Oral Maxillofac Surg 2003;61(5):636-7. http://dx.doi. org/10.1053/joms.2003.50123.

26. Cherniak OS, Fesenko II. Effectiveness of ultrasound in verification of the mucus plugs and sialoliths of the Wharton's duct. J Diagn Treat Oral Maxillofac Pathol 2019;3(5):144-53. http://dx.doi.org/10.23999/j. dtomp.2019.5.3. 